\title{
BMJ Open Cost-effectiveness of single-dose zoledronic acid for nursing home residents with osteoporosis in the USA
}

Kouta Ito ${ }^{1,2}$

To cite: Ito K. Costeffectiveness of single-dose zoledronic acid for nursing home residents with osteoporosis in the USA. BMJ Open 2018;8:e022585. doi:10.1136/ bmjopen-2018-022585

- Prepublication history for this paper is available online. To view these files, please visit the journal online (http://dx.doi. org/10.1136/bmjopen-2018022585).

This study was presented at the International Society for Pharmacoeconomics and Outcomes Research 22nd Annual International Meeting, Boston, Massachusetts, 20-24 May 2017.

Received 27 February 2018

Revised 8 June 2018

Accepted 24 July 2018

\section{Check for updates}

\section{(c) Author(s) (or their} employer(s)) 2018. Re-use permitted under CC BY-NC. No commercial re-use. See rights and permissions. Published by BMJ.

${ }^{1}$ Department of Medicine, Hebrew SeniorLife, Roslindale, Massachusetts, USA

${ }^{2}$ Division of Gerontology, Department of Medicine, Beth Israel Deaconess Medical Center, Boston, Massachusetts, USA

Correspondence to

Dr Kouta Ito;

Koutalto@hsl.harvard.edu

\section{ABSTRACT}

Objective To evaluate the cost-effectiveness of routine administration of single-dose zoledronic acid for nursing home residents with osteoporosis in the USA.

Design Markov cohort simulation model based on published literature from a healthcare sector perspective over a lifetime horizon.

Setting Nursing homes.

Participants A hypothetical cohort of nursing home residents aged 85 years with osteoporosis.

Interventions Two strategies were compared: (1) a single intravenous dose of zoledronic acid $5 \mathrm{mg}$ and (2) usual care (supplementation of calcium and vitamin D only). Primary and secondary outcome measures Incremental cost-effectiveness ratio (ICER), as measured by cost per quality-adjusted life year (QALY) gained.

Results Compared with usual care, zoledronic acid had an ICER of $\$ 207400$ per QALY gained and was not costeffective at a conventional willingness-to-pay threshold of $\$ 100000$ per QALY gained. The results were robust to a reasonable range of assumptions about incidence, mortality, quality-of-life effects and the cost of hip fracture and the cost of zoledronic acid. Zoledronic acid had a potential to become cost-effective if a fracture risk reduction with zoledronic acid was higher than $23 \%$ or if 6-month mortality in nursing home residents was lower than $16 \%$. Probabilistic sensitivity analysis showed that the zoledronic acid would be cost-effective in 14\%, $27 \%$ and $44 \%$ of simulations at willingness-to-pay thresholds of $\$ 50000, \$ 100000$ or $\$ 200000$ per QALY gained, respectively.

Conclusions Routine administration of singledose zoledronic acid in nursing home residents with osteoporosis is not a cost-effective use of resources in the USA but could be justifiable in those with a favourable life expectancy.

\section{INTRODUCTION}

Hip fracture sustained in nursing homes is an important source of mortality, morbidity and healthcare expenditure. Nursing home residents account for approximately $8 \%$ of hip fracture in the USA, meaning that someone breaks hip every $23 \mathrm{~min}$ in nursing homes. ${ }^{1}$ More than one in three nursing home residents die and more than a half either die or develop total dependence within 6 months
Strengths and limitations of this study

A Markov cohort simulation model was developed based on currently available evidence to simulate the prognosis of nursing home residents with osteoporosis.

- The fracture-reduction benefit of zoledronic acid was calculated using a surrogate outcome of bone mineral density (BMD), although the change in BMD can be used as supportive evidence of the effectiveness of treatment and may be useful to guide clinical practice and policy-making until a clinical trial measuring fracture as a primary outcome is available.

> Our findings were robust to a reasonable range of assumptions about the incidence, excess mortality, quality-of-life effects, and cost of hip fracture and the cost of zoledronic acid.

- Two-way sensitivity analyses were performed by simultaneously altering relative risk of hip fracture with zoledronic acid and 6-month mortality in nursing home residents.

of hip fracture, ${ }^{23}$ and there is little recovery of quality of life over 1 year of hip fracture. ${ }^{4}$ Resource utilisations (eg, hospitalisation, emergency department visit, and contacts with physicians and therapists) increase substantially through 6 months after hip fracture. ${ }^{5}$ Although hip fracture in nursing home residents is a compelling public health problem, the optimal fracture prevention strategy in this population remains an open question. Osteoporosis, a strong risk factor for hip fracture, ${ }^{67}$ is widespread with a prevalence of up to $85 \%$ in nursing homes. ${ }^{78}$ Nevertheless, the use of pharmacological agents for osteoporosis is uncommon among nursing home residents. ${ }^{9-12}$ Little is known about cost-effectiveness of pharmacotherapy for osteoporosis in nursing home residents. A recent clinical trial in frail institutionalised women with osteoporosis (the Zoledronic Acid in frail Elders to Strengthen bone (ZEST) study) demonstrated that a single intravenous dose of zoledronic acid $5 \mathrm{mg}$ successfully increased bone mineral density (BMD) over 2 years. ${ }^{13}$ The 


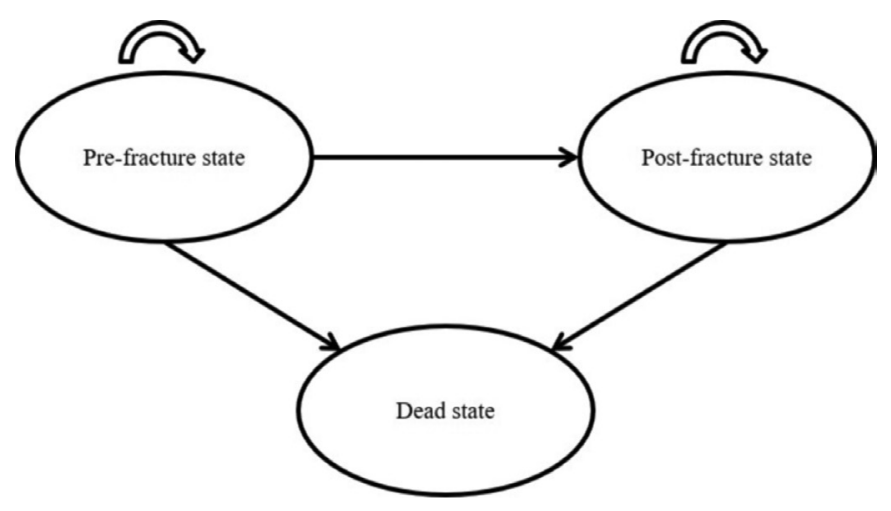

Figure 1 The Markov model structure.

change in BMD can be used as supportive evidence of the effectiveness of treatment and may be useful to guide clinical practice and policy-making until a clinical trial measuring fracture as a primary outcome is available. ${ }^{14}$ The objective of this study was to estimate the health and economic effect of routine administration of singledose zoledronic acid in nursing home residents with osteoporosis.

\section{METHODS}

A Markov cohort simulation model was developed to simulate the prognosis of nursing home residents with osteoporosis. It was based on the previous published models of fracture prevention, which mirrored models used to support clinical practice guidelines in various countries, and adopted a healthcare sector perspective, a lifetime horizon and a discount rate of $3 \%$ per year for both health outcomes and costs. ${ }^{15-18}$ The analysis was performed using TreeAge Pro Suite 2016 software (TreeAge Software, Williamstown, Massachusetts, USA).

\section{Population}

The target population reflected the participants of the ZEST study. ${ }^{13}$ It was a hypothetical cohort of women aged 85 years who resided in nursing homes with low BMD (a T-score of $\leq-2.0$ ) at the spine, hip or radius. Those with cognitive and functional impairment, immobility, multiple medical conditions, and who were prescribed multiple medications were included. Those with a projected life expectancy less than 2 years or an estimated glomerular filtration rate below $30 \mathrm{~mL} / \mathrm{min}$ were excluded.

\section{Strategies}

The model compared two strategies: (1) single intravenous dose of zoledronic acid and (2) usual care. Those in the zoledronic acid group received intravenous administration of zoledronic acid $5 \mathrm{mg}$ over $45 \mathrm{~min}$ at their nursing homes. It was assumed a basic metabolic panel was ordered and comprehensive oral examination was performed prior to initiation of zoledronic acid. Those in the usual care group were observed without additional pharmacotherapy for osteoporosis. In both groups, residents received a daily supplementation of calcium
(1200 mg) and vitamin D (800 IU). It was assumed that all residents who sustained hip fracture were hospitalised for operative management and returned to their nursing homes for postacute rehabilitation and subsequent longterm care.

\section{Model}

The model allocated and subsequently reallocated a cohort of nursing home residents into one of mutually exclusive health states (ie, prefracture, postfracture, or dead) (figure 1). They entered the model in the prefracture state. Every 6 months, they were at risk for sustaining hip fracture. If they survived hip fracture, they moved into the postfracture state. If not, they moved into the dead state. Throughout their lifetime, all residents were at risk for death from causes unrelated to hip fracture. The model restricted analysis to hip fracture because the relationship between BMD and fracture rates seems less robust for other types of fracture (eg, vertebrae, wrist, proximal humerus, pelvis, rib and tibia/fibula). Each health state was assigned a quality-of-life weight (ie, utility) and a cost. Transitions occurred from one state to another every 6 months according to transition probabilities obtained from published sources.

\section{Parameters}

Model parameters are summarised in table 1 and described in greater detail below.

\section{Fracture incidence}

The incidence rate of hip fracture in nursing home residents was taken from a cohort study of Medicare claims linked with the Minimum Data Set (MDS). ${ }^{1}$

\section{Effectiveness of zoledronic acid}

Fracture-reduction benefits observed in younger, less frail, community-dwelling women (eg, the Health Outcomes and Reduced Incidence with Zoledronic Acid Once Yearly Pivotal Fracture Trial (HORIZON-PFT) and the HORIZON Recurrent Fracture Trial (HORIZON-RFT)) might not be generalisable to older, more frail nursing home residents. The efficacy of once-yearly zoledronic acid that was evaluated by the HORIZON-PFT and the HOROZON-RFT might not be generalisable to singledose zoledronic acid. ${ }^{19} 20$ The post-hoc analyses for older adults or for single-dose zoledronic acid based on the HORIZON-PFT and the HORIZON-RFT were considered rather exploratory. ${ }^{21} 22$ Therefore, we simulated changes in BMD over time and predicted the incidence of hip fractures as a function of age and BMD. We simulated changes in BMD over time and predicted the incidence of hip fractures as a function of age and BMD. The fracture-reduction benefit of zoledronic acid was calculated using a surrogate outcome of total hip BMD that was taken from the ZEST study. ${ }^{13}$ It was converted into the relative risk of hip fracture based on a cohort study of nursing home residents. ${ }^{623}$ As a result, the estimated relative risk of hip fracture with zoledronic acid was 0.85 . Because $\mathrm{BMD}$ is a surrogate marker for fracture risk reduction, 
Table 1 Model parameters

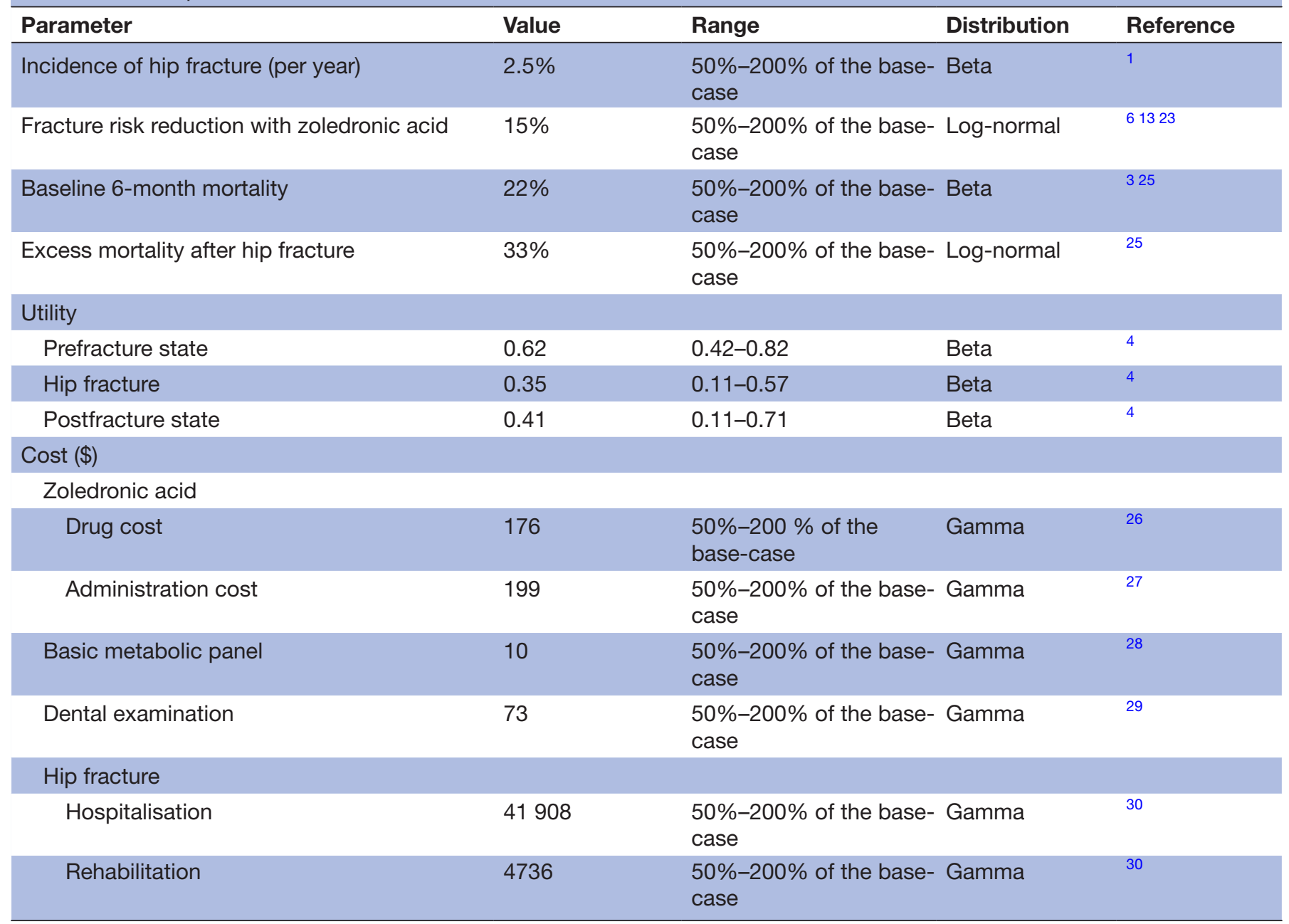

the model varied the assumption widely in sensitivity analyses to explore its impact on the study conclusion. It was assumed that zoledronic acid did not offer protection from hip fracture in the first 18 months based on a post-hoc analysis of clinical trials of zoledronic acid in postmenopausal women. ${ }^{24}$ It was also assumed that the fracture-reduction benefit of zoledronic acid persisted over 3 years after administration based on post-hoc analyses of clinical trials of zoledronic acid in men and women with hip fracture. ${ }^{22}$

\section{Survival outcomes}

The mortality rate in the first 6 months after hip fracture was taken from a cohort study of Medicare claims linked with the MDS. ${ }^{3}$ Mortality in those who were with a similar health status and function but did not sustain hip fracture was not available. Because of a paucity of large-scale data in the USA, their mortality rate was estimated using relative excess mortality after hip fracture based on a claim-based cohort study in Germany. ${ }^{25}$ The model varied the assumption widely in sensitivity analyses to explore its impact on the study conclusion. It was assumed that excess mortality was limited to the first 6 months after hip fracture.
Quality of life

Because of limited data addressing quality-of-life effects of hip fracture on nursing home residents in the USA, they were estimated based on a prospective longitudinal study in Canada. ${ }^{4}$ Utilities for the prefracture and postfracture states and temporary utility loss from hip fracture were based on EuroQol Five Dimensional Questionnaire (EQ-5D) scores. The model varied the assumption widely in sensitivity analyses to explore its impact on the study conclusion.

\section{Cost}

The drug price of generic zoledronic acid was taken from an online source of drug information. ${ }^{26}$ The administration cost of zoledronic acid was obtained from a microcosting analysis in patients with metastatic bone disease. ${ }^{27}$ The cost of basic metabolic panel (current procedural terminology (CPT) code 80048) was based on the Medicare reimbursement, and the cost of comprehensive oral examination (current dental terminology (CDT) code D 0150) was based on the national average of commercial rates. ${ }^{28} 29$ The hospitalisation and rehabilitation costs of hip fracture were taken from a cost analysis of a large managed care organisation. ${ }^{30}$ The model assumed 
that excess resource utilisation was limited to the first 6 months after hip fracture. ${ }^{5}$ All costs were inflated to 2017 dollars using the Consumer Price Index for Medical Care for All Urban Consumers. ${ }^{31}$

\section{Base-case analysis}

The incremental cost-effectiveness ratio (ICER) of a strategy was calculated as the additional cost of that strategy $(\Delta$ cost $)$ divided by its additional health benefit ( $\Delta$ quality-adjusted life years; QALYs) compared with the competing strategy. The model sought to identify the strategy that would provide the greatest improvement in health outcomes at a willingness-to-pay (WTP) threshold of $\$ 100000$ per QALY gained.

\section{Sensitivity analyses}

To assess the robustness of our findings, deterministic one-way sensitivity analyses were performed. Ranges from 95\% CIs were tested when available; otherwise, ranges from $50 \%$ to $200 \%$ of the base-case estimates were tested. Two-way sensitivity analyses were performed by simultaneously altering relative risk of hip fracture with zoledronic acid and 6-month mortality in nursing home residents. A probabilistic sensitivity analysis was also conducted, in which the model was run using a value for each parameter down randomly from the distribution assigned to that parameter. The model used beta distributions for probabilities, log-normal distributions for relative risks, and gamma distributions for utilities and costs. The model ran 100000 iterations to generate a cost-effectiveness acceptability curve showing the probability that either strategy was cost-effective varying WTP thresholds.

\section{Patient and public involvement}

The study design was a secondary data analysis and did not directly involve patients or public.

\section{RESULTS}

\section{Base-case analysis}

The mean survival in both the usual care group and the zoledronic acid group was approximately 2.3 years. The lifetime risk of hip fracture was $5.4 \%$ in the usual care group and $5.1 \%$ in the zoledronic acid group. Compared with usual care, zoledronic acid improved quality-adjusted survival by 0.0015 QALYs, increased cost by $\$ 320$ and had an ICER of $\$ 207400$ per QALY gained (table 2).

Therefore, usual care was preferred at a conventional WTP threshold of $\$ 100000$ per QALY gained.

\section{Sensitivity analyses}

Our findings were robust to a reasonable range of assumptions about the incidence, excess mortality, quality-of-life effects, cost of hip fracture and the cost of zoledronic acid. Our findings were sensitive to the assumptions about the fracture-reduction benefit of zoledronic acid. Zoledronic acid became increasingly more cost-effective as relative risk of hip fracture with zoledronic acid decreased. Zoledronic acid would become preferred if relative risk of fracture with zoledronic acid was lower than 0.77 (ie, a fracture risk reduction of 23\%). Our findings were also sensitive to the assumption about 6-month mortality in nursing home residents. Zoledronic acid became increasingly more cost-effective as 6-month mortality decreased. Zoledronic acid would become preferred if 6-month mortality in nursing home residents was lower than $16 \%$. Figure 2 summarises two-way sensitivity analyses of relative risk of hip fracture with zoledronic acid and 6-month mortality in nursing home residents. For example, under the best-case assumption that 6 -month mortality was a half of the base-case estimate (ie, $11 \%$ ), zoledronic acid would be preferred if relative risk of hip fracture with zoledronic acid was lower than 0.90 (ie, a fracture risk reduction of $10 \%)$. Under the worst-case assumption that 6-month mortality was twice as high as the base-case estimate (ie, $44 \%$ ), zoledronic acid would be preferred if relative risk of hip fracture with zoledronic acid was lower than 0.06 (ie, a fracture risk reduction of $94 \%$ ). If 6-month mortality exceeded $45 \%$, zoledronic acid would not be preferred regardless of the fracture-reduction benefit of zoledronic acid. The result of the probability sensitivity analysis is displayed in the cost-effectiveness acceptability curve (figure 3 ). The curve indicates that zoledronic acid would be cost-effective in $14 \%, 27 \%$ and $44 \%$ of simulations at WTP thresholds of $\$ 50000, \$ 100000$ or $\$ 200000$ per QALY gained, respectively.

\section{DISCUSSION}

The present study found that routine administration of single-dose zoledronic acid in nursing home residents with osteoporosis is not a good investment from a healthcare sector perspective in the USA. The study conclusion was not altered by a wide range of plausible estimates of fracture-related parameters (ie, incidence, excess mortality, quality-of-life effects and cost of hip fracture) and medication-related parameters (ie, drug price, administration cost, laboratory test and dental examination). A critical

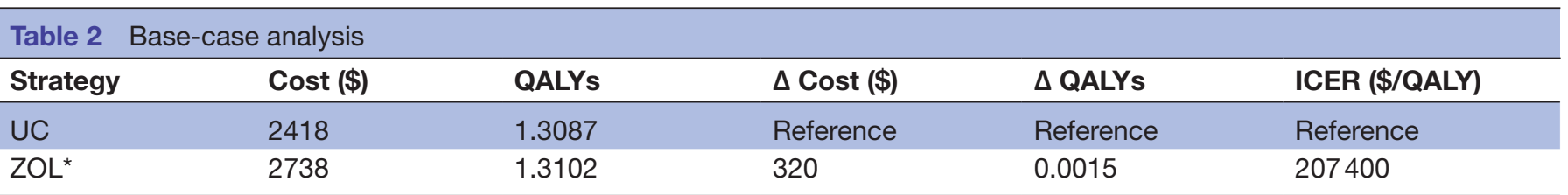

*Single intravenous dose.

ICER, incremental cost-effectiveness ratio; QALY, quality-adjusted life year; UC, usual care; ZOL, zoledronic acid. 


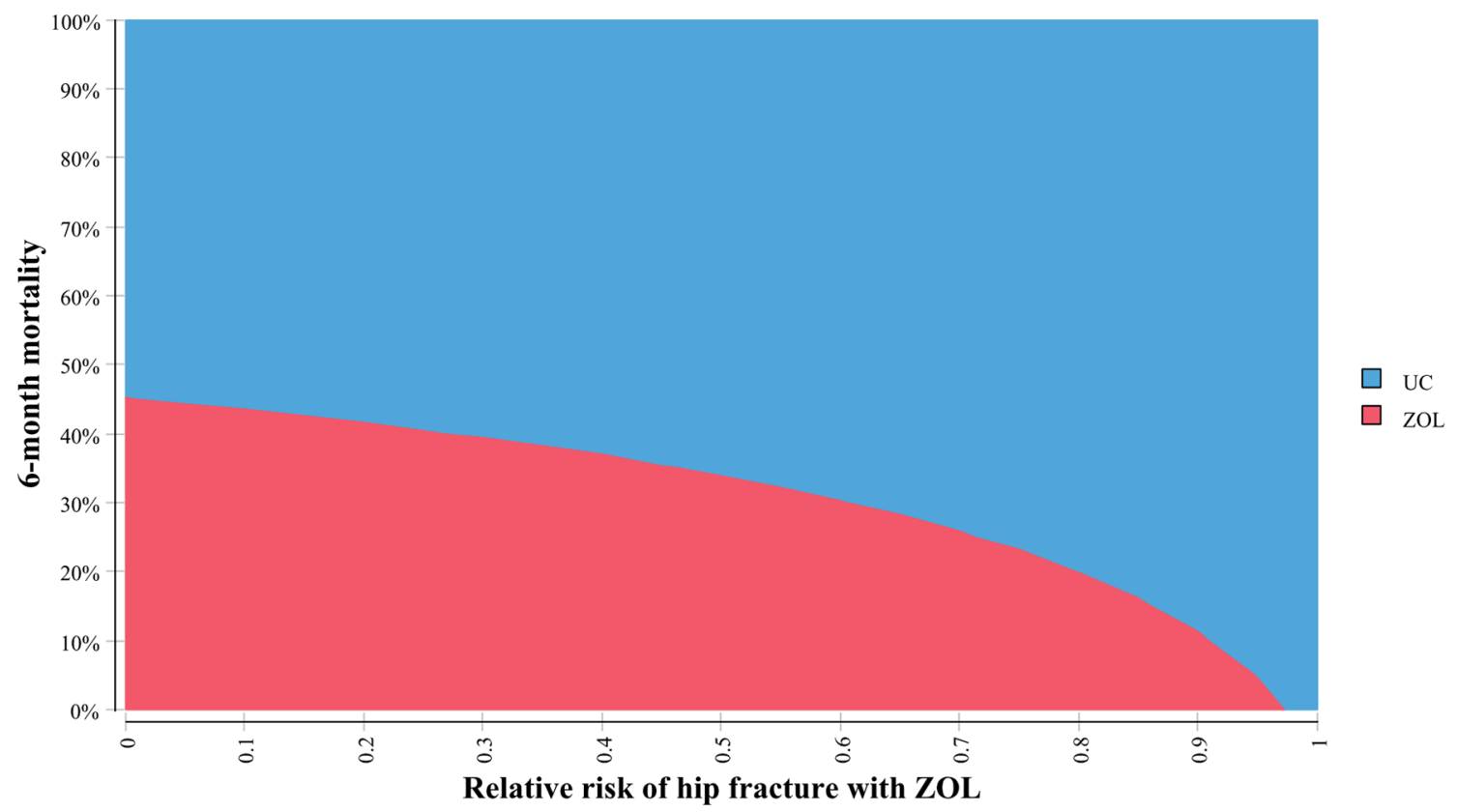

Figure 2 Two-way sensitivity analysis of the relative risk of hip fracture with zoledronic acid and 6-month mortality in nursing home residents. The area represents a preferred strategy, either usual care (UC) or single intravenous dose of zoledronic acid (ZOL), at a willingness-to-pay threshold of $\$ 100000$ per quality-adjusted life year gained.

question, the answer to which could dramatically influence decision-making regarding the use of zoledronic acid, is whether an increase in BMD translates into a decreased risk of hip fracture. The base-case estimate of a $15 \%$ fracture risk reduction with zoledronic acid is more conservative than the estimate used in a conventional cost-effectiveness analysis of osteoporosis treatment. ${ }^{32}$ The sensitivity analysis showed that zoledronic acid had a potential to become reasonably cost-effective if the risk of hip fracture was reduced by $23 \%$ or more, which is comparable with a fracture risk reduction observed in the post-hoc analysis of the clinical trial in younger, less frail, community-dwelling women. ${ }^{22}$ These assumptions need to be confirmed in a larger scale clinical trial with a longer follow-up period in older, more frail nursing home residents. ${ }^{33}$ Clinical decision-making for nursing home residents is also strongly influenced by their prognosis and competing risk of death. The sensitivity analysis showed that zoledronic acid had a potential to become reasonably cost-effective if residents had 6-month mortality of

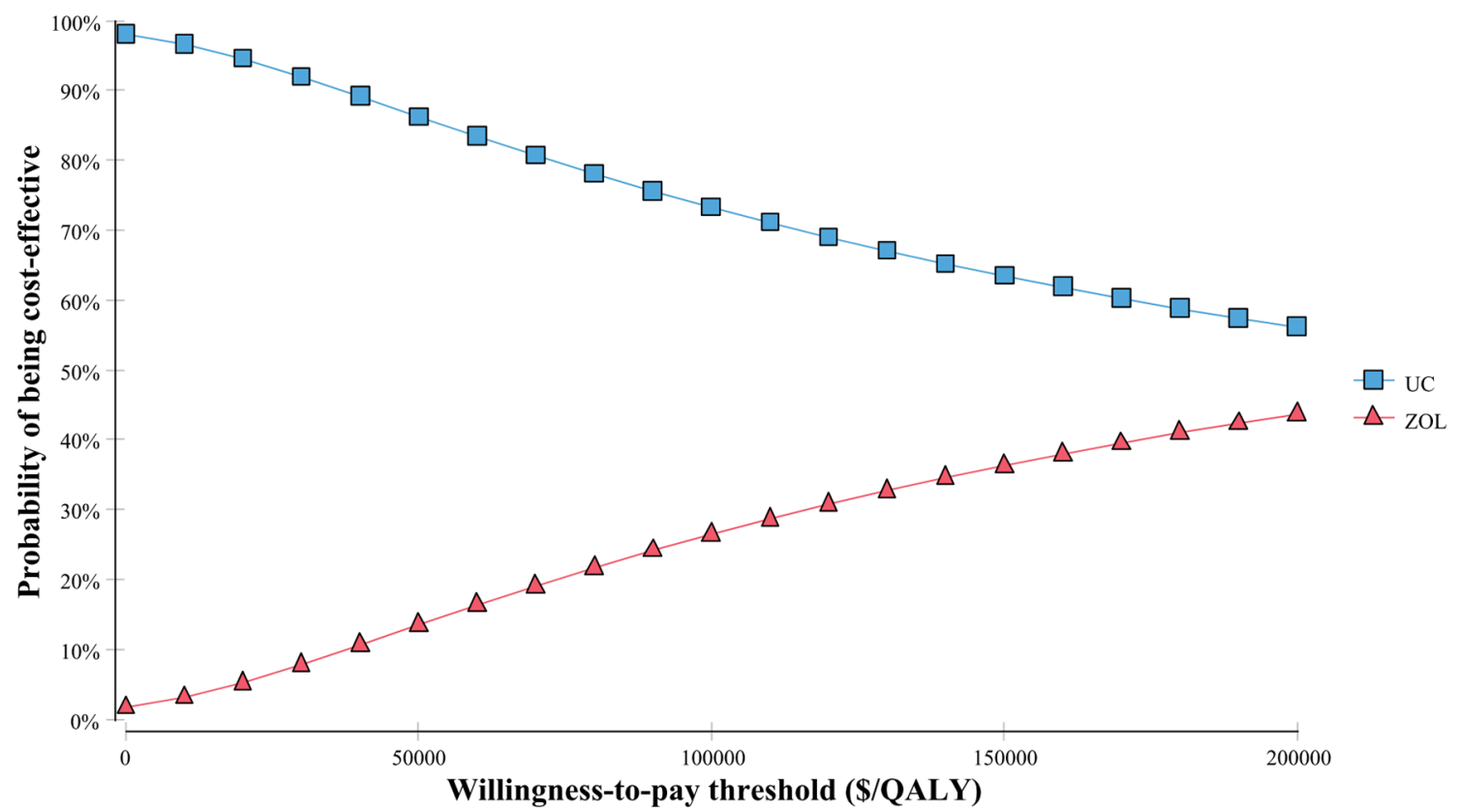

Figure 3 Cost-effectiveness acceptability curve. A graph plotted a range of willingness-to-pay thresholds on the horizontal axis against the probability that either usual care (UC) or single intravenous dose of zoledronic acid (ZOL) would be costeffective at that willingness-to-pay threshold on the vertical axis. QALY, quality-adjusted life year. 
$16 \%$ or below which was lower than overall mortality (ie, $23 \%$ ) observed in a large cohort of nursing home residents in the USA. ${ }^{34}$ These results are encouraging and suggest that a single infusion of zoledronic acid can be a viable option when treatment is targeted to those with a more favourable prognosis. On the contrary, for those with a less favourable prognosis (ie, 6-month mortality of $45 \%$ or above), zoledronic acid is not a viable option regardless of its fracture-reduction benefit.

There are a limited number of clinical trials that evaluated fracture prevention in nursing home residents. Previous analyses demonstrated the use of hip protectors could be reasonably cost-effective in nursing home residents. ${ }^{35}{ }^{36}$ However, their fracture-reduction benefit was not robust based on a more recent systematic review. ${ }^{37}$ Moreover, poor adherence to hip protectors might limit widespread implementation in the real world. ${ }^{38}$ The efficacy of oral bisphosphonates (eg, alendronate) was previously evaluated in younger, more independent residents from assisted living communities, and the incremental change in BMD was comparable with that observed in the clinical trial of zoledronic acid in older, more dependent residents. ${ }^{13} 39$ However, administration of oral bisphosphonates in nursing homes may impose an additional effort to ensure proper dosing technique for avoiding gastrointestinal adverse events. One-time administration of zoledronic acid in the more controlled nursing home setting may potentially resolve the issue of poor adherence and also reduce the burden on not only nursing staffs but also residents with cognitive deficits and poor functional status.

The following limitations are worth noting. By excluding the effect of non-hip fractures, the model might have underestimated the total health benefit of zoledronic acid. The model did not incorporate adverse events of zoledronic acid (eg, osteonecrosis of the jaw), which could have a negative impact on quality of life, but no good empirical estimates of these events were available. The study targeted nursing home residents who had already been diagnosed with osteoporosis and did not consider screening for osteoporosis, which could be logistically challenging in the nursing home setting.

Based on currently available evidence, routine administration of single-dose zoledronic acid for nursing home residents with osteoporosis is not a cost-effective use of resources in the USA, but could be justifiable in those with a favourable life expectancy. The study findings should be confirmed by a clinical trial measuring fracture as a primary outcome in this population.

Contributors $\mathrm{KI}$ is the sole author and contributed to conception and design, collection and assembly of data, data analysis and interpretation, and manuscript writing.

Funding The authors have not declared a specific grant for this research from any funding agency in the public, commercial or not-for-profit sectors.

Competing interests None declared.

Patient consent Not required.

Provenance and peer review Not commissioned; externally peer reviewed.
Data sharing statement Study protocol is available from KI (email, Koutalto@hsl. harvard.edu). Statistical code and data sets are not available.

Open access This is an open access article distributed in accordance with the Creative Commons Attribution Non Commercial (CC BY-NC 4.0) license, which permits others to distribute, remix, adapt, build upon this work non-commercially, and license their derivative works on different terms, provided the original work is properly cited, appropriate credit is given, any changes made indicated, and the use is non-commercial. See: http://creativecommons.org/licenses/by-nc/4.0/.

\section{REFERENCES}

1. Berry SD, Lee $Y$, Zullo AR, et al. Incidence of hip fracture in U.S. nursing homes. J Gerontol A Biol Sci Med Sci 2016;71:1230-4.

2. Berry SD, Samelson EJ, Bordes M, et al. Survival of aged nursing home residents with hip fracture. J Gerontol A Biol Sci Med Sci 2009;64A:771-7.

3. Neuman MD, Silber JH, Magaziner JS, et al. Survival and functional outcomes after hip fracture among nursing home residents. JAMA Intern Med 2014;174:1273-80.

4. Beaupre LA, Jones CA, Johnston DW, et al. Recovery of function following a hip fracture in geriatric ambulatory persons living in nursing homes: prospective cohort study. J Am Geriatr Soc 2012;60:1268-73.

5. Zimmerman S, Chandler JM, Hawkes W, et al. Effect of fracture on the health care use of nursing home residents. Arch Intern Med 2002;162:1502-8.

6. Broe KE, Hannan MT, Kiely DK, et al. Predicting fractures using bone mineral density: a prospective study of long-term care residents. Osteoporos Int 2000;11:765-71.

7. Chandler JM, Zimmerman SI, Girman CJ, et al. Low bone mineral density and risk of fracture in white female nursing home residents. JAMA 2000;284:972-7.

8. Zimmerman SI, Girman CJ, Buie VC, et al. The prevalence of osteoporosis in nursing home residents. Osteoporos Int 1999;9:151-7.

9. Wright RM. Use of osteoporosis medications in older nursing facility residents. J Am Med Dir Assoc 2007;8:453-7.

10. Parikh S, Avorn J, Solomon DH. Pharmacological management of osteoporosis in nursing home populations: a systematic review. J Am Geriatr Soc 2009;57:327-34.

11. Parikh S, Brookhart MA, Stedman M, et al. Correlations of nursing home characteristics with prescription of osteoporosis medications. Bone 2011;48:1164-8.

12. Sawka AM, Ismaila N, Cranney A, et al. A scoping review of strategies for the prevention of hip fracture in elderly nursing home residents. PLoS One 2010;5:e9515.

13. Greenspan SL, Perera S, Ferchak MA, et al. Efficacy and safety of single-dose zoledronic acid for osteoporosis in frail elderly women: a randomized clinical trial. JAMA Intern Med 2015;175:913-21.

14. U.S. Department of Health and Human Services. Bone Health and Osteoporosis: a report of the surgeon general. Rockville, MD: U.S. Department of Health and Human Service, Office of the Surgeon General, 2004.

15. Ito K, Hollenberg JP, Charlson ME. Using the osteoporosis selfassessment tool for referring older men for bone densitometry: a decision analysis. J Am Geriatr Soc 2009;57:218-24.

16. Ito K, Elkin EB, Girotra M, et al. Cost-effectiveness of fracture prevention in men who receive androgen deprivation therapy for localized prostate cancer. Ann Intern Med 2010;152:621-9.

17. Ito K, Blinder VS, Elkin EB. Cost effectiveness of fracture prevention in postmenopausal women who receive aromatase inhibitors for early breast cancer. J Clin Oncol 2012;30:1468-75.

18. Ito K, Leslie WD. Cost-effectiveness of fracture prevention in rural women with limited access to dual-energy X-ray absorptiometry. Osteoporos Int 2015;26:2111-9.

19. Black DM, Delmas PD, Eastell R, et al. Once-yearly zoledronic acid for treatment of postmenopausal osteoporosis. N Engl J Med 2007;356:1809-22.

20. Lyles KW, Colón-Emeric CS, Magaziner JS, et al. Zoledronic acid and clinical fractures and mortality after hip fracture. $N$ Engl $\mathrm{J}$ Med 2007;357:1799-809.

21. Boonen S, Black DM, Colón-Emeric CS, et al. Efficacy and safety of a once-yearly intravenous zoledronic acid $5 \mathrm{mg}$ for fracture prevention in elderly postmenopausal women with osteoporosis aged 75 and older. J Am Geriatr Soc 2010;58:292-9.

22. Reid IR, Black DM, Eastell $R$, et al. Reduction in the risk of clinical fractures after a single dose of zoledronic Acid 5 milligrams. J Clin Endocrinol Metab 2013;98:557-63. 
23. De Laet $\mathrm{CE}$, van Hout $\mathrm{BA}$, Burger $\mathrm{H}$, et al. Bone density and risk of hip fracture in men and women: cross sectional analysis. BMJ 1997;315:221-5.

24. Boonen S, Eastell R, Su G, et al. Time to onset of antifracture efficacy and year-by-year persistence of effect of zoledronic acid in women with osteoporosis. J Bone Miner Res 2012;27:1487-93.

25. Rapp K, Becker C, Lamb SE, et al. Hip fractures in institutionalized elderly people: incidence rates and excess mortality. J Bone Miner Res 2008;23:1825-31.

26. Drugs.com. Zoledronic acid prices, coupons and patient assistance programs. https://www.drugs.com/price-guide/zoledronic-acid (accessed 31 Jan 2018)

27. DesHarnais Castel L, Bajwa K, Markle JP, et al. A microcosting analysis of zoledronic acid and pamidronate therapy in patients with metastatic bone disease. Support Care Cancer 2001;9:545-51.

28. Center for Medicare and Medicaid Services. Clinical laboratory fee schedule. https://www.cms.gov/Medicare/Medicare-Fee-for-ServicePayment/ClinicalLabFeeSched/index.html (accessed 31 Jan 2018).

29. California Department of Health Care Services. Medi-Cal dental service rate review. http://www.dhcs.ca.gov/services/Documents/ 2015_Dental-Services-Rate-Review.pdf (accessed 31 January 2018).

30. Ohsfeldt RL, Borisov NN, Sheer RL. Fragility fracture-related direct medical costs in the first year following a nonvertebral fracture in a managed care setting. Osteoporosis Int 2006;17:252-8.

31. United States Department of Labors. Bureau of Labor Statistics. Consumer Price Index. http://www.bls.gov/cpi/ (accessed 31 Jan 2018).
32. Tosteson AN, Melton LJ, Dawson-Hughes B, et al. Cost-effective osteoporosis treatment thresholds: the United States perspective. Osteoporos Int 2008;19:437-47.

33. ClinicalTrial.gov. Zoledronic acid for osteoporotic fracture prevention (ZEST II). https://clinicaltrials.gov/ct2/show/NCT02589600 (accessed 31 Jan 2018)

34. Porock D, Oliver DP, Zweig S, et al. Predicting death in the nursing home: development and validation of the 6-month Minimum Data Set mortality risk index. J Gerontol A Biol Sci Med Sci 2005;60:491-8

35. Colón-Emeric CS, Datta SK, Matchar DB. An economic analysis of external hip protector use in ambulatory nursing facility residents. Age Ageing 2003;32:47-52.

36. Honkanen LA, Schackman BR, Mushlin Al, et al. A cost-benefit analysis of external hip protectors in the nursing home setting. $J$ Am Geriatr Soc 2005;53:190-7.

37. Santesso N, Carrasco-Labra A, Brignardello-Peterson R. Hip protectors for preventing hip fractures in older people. Cochrane Database Syst Rev 2014;31:CD001255.

38. Zimmerman S, Magaziner J, Birge SJ, et al. Adherence to hip protectors and implications for U.S. long-term care settings. J Am Med Dir Assoc 2010;11:106-15.

39. Greenspan SL, Schneider DL, McClung MR, et al. Alendronate improves bone mineral density in elderly women with osteoporosis residing in long-term care facilities. A randomized, double-blind, placebo-controlled trial. Ann Intern Med 2002;136:742-6. 